\title{
OSTEOCONDROMATOSE MÚLTIPLA HEREDITÁRIA: RELATO DE UM CASO CLÍNICO FAMILIAR
}

\author{
ARTIGO ORIGINAL \\ EL-HUSNY, Antonette Souto ${ }^{1}$ \\ DIAS, Amanda de Araújo ${ }^{2}$ \\ MARTINS, Bianca Azevedo Parreira ${ }^{3}$ \\ BORGES, Samuel Maurício Ferreira ${ }^{4}$ \\ MOREIRA, Elisângela Claudia de Medeiros ${ }^{5}$ \\ DENDASCK, Carla Viana ${ }^{6}$ \\ OLIVEIRA, Ciane Martins de ${ }^{7}$
}

${ }^{1}$ Doutora em Genética Médica. Docente e Pesquisadora do Centro Universitário do Estado do Pará (CESUPA).

${ }^{2}$ Acadêmica de Medicina do Centro Universitário do Estado do Pará (CESUPA).

${ }^{3}$ Acadêmica de Medicina do Centro Universitário do Estado do Pará (CESUPA).

${ }^{4}$ Acadêmico de Medicina do Centro Universitário do Estado do Pará (CESUPA).

5 Mestre em Teoria e Pesquisa do Comportamento. Docente da Universidade do Estado do Pará - UEPA. Doutoranda em Doenças Tropicais na Universidade Federal do Pará - NMT/UFPA.

6 Teóloga. Doutora em Psicanálise Clínica. Pesquisadora do Centro de Pesquisa e Estudos Avançados, São Paulo, SP.

7 Doutora em Ciências Biológicas. Docente e Pesquisadora do Centro Universitário do Estado do Pará (CESUPA). 
OLIVEIRA, Euzébio de ${ }^{8}$

EL-HUSNY, Antonette Souto. Et al. Osteocondromatose Múltipla Hereditária: relato de um caso clínico familiar. Revista Científica Multidisciplinar Núcleo do Conhecimento. Ano 04, Ed. 12, Vol. 07, pp. 24-29. Dezembro de 2019. ISSN: 24480959, Link de acesso: https://www.nucleodoconhecimento.com.br/saude/osteocondromatosemultipla

\section{RESUMO}

Introdução: A Osteocondromatose Múltipla Hereditária $(\mathrm{OMH})$ ou Exostose Múltipla é uma doença autossômica dominante rara (1:50.000) e sua manifestação se dá pela presença de osteocondromas múltiplos, causando retardo no crescimento ósseo longitudinal e deformidades ósseas. Objetivo: relatar caso de família acometida por OMH atendida no ambulatório de Genética do Centro Universitário do Estado do Pará (CESUPA), localizado em Belém - PA. Relato de caso: Foram avaliados 3 indivíduos aparentados de 9, 11 e 23 anos apresentando múltiplas protuberâncias de consistência óssea disseminadas pelo corpo com história familiar positiva e padrão de herança autossômico dominante. Conclusão: Embora seja uma doença rara, é importante que seja prontamente reconhecida para viabilizar 0 adequado acompanhamento ortopédico e aconselhamento genético familiar.

Descritores: Genética, Exostose Múltipla Hereditária.

${ }^{8}$ Doutor em Medicina/Doenças Tropicais. Docente e Pesquisador na Universidade Federal do Pará - UFPA. Pesquisador Colaborador do Núcleo de Medicina Tropical NMT/UFPA. 


\section{INTRODUÇÃO}

A Osteocondromatose Múltipla Hereditária $(\mathrm{OMH})$ ou Exostose Multipla é uma doença autossômica dominante rara (1:50.000) (STEINER, 1992; HARMS, 1992), associada a alterações nos genes EXT1 e EXT2 (HECHT, 1995).

Sua manifestação se dá pela presença de osteocondromas múltiplos, causando retardo no crescimento ósseo longitudinal e deformidades ósseas (MURPHEY, 2000).

Embora o fator estético seja predominante, os casos devem ser reconhecidos e terem acompanhamento clínico-radiológico em serviço especializado, não somente para a avaliação do desenvolvimento das deformidades ósseas, como também para a identificação de possíveis focos com potencial para malignização (KHURANA, 2002).

\section{OBJETIVO}

Relatar o caso de familiar acometida por $\mathrm{OMH}$ atendida no ambulatório de Genética do Centro Universitário do Estado do Pará (CESUPA), localizado em Belém - PA.

\section{RELATO DE CASO}

Foram avaliados 3 indivíduos aparentados de 9, 11 e 23 anos, respectivamente, apresentando múltiplas protuberâncias de consistência óssea disseminadas pelo corpo com história familiar positiva e padrão de herança autosômico dominante para a osteocondromatose.

Estes apresentavam variados acometimentos osteoarticulares, que incluem escoliose, crepitações, deformidades, assimetrias, além de inúmeros osteocondromas. Os exames radiográficos foram compatíveis com diagnóstico de $\mathrm{OMH}$, como já se suspeitava.

Infelizmente, o serviço não dispõe de análises moleculares para esta doença, para analisar mais a fundo as questões da herança genética. Apesar da dificuldade de diagnóstico molecular, este grupo de pacientes permanece em seguimento ortopédico 
regular, baseado em suas características clínicas e de padrão hereditário, com vistas a possibilitar intervenções clínicas e cirúrgicas, caso necessário, bem como o controle da evolução da doença para a malignidade.

Figura 1. Heredograma. Indivíduos afetados apresentam Osteocomatose Múltipla Hereditária, e são atendidos no ambulatório de genética do Centro de Especialidades Médicas (CEMEC) do Centro Universitário do Estado do Pará (CESUPA).

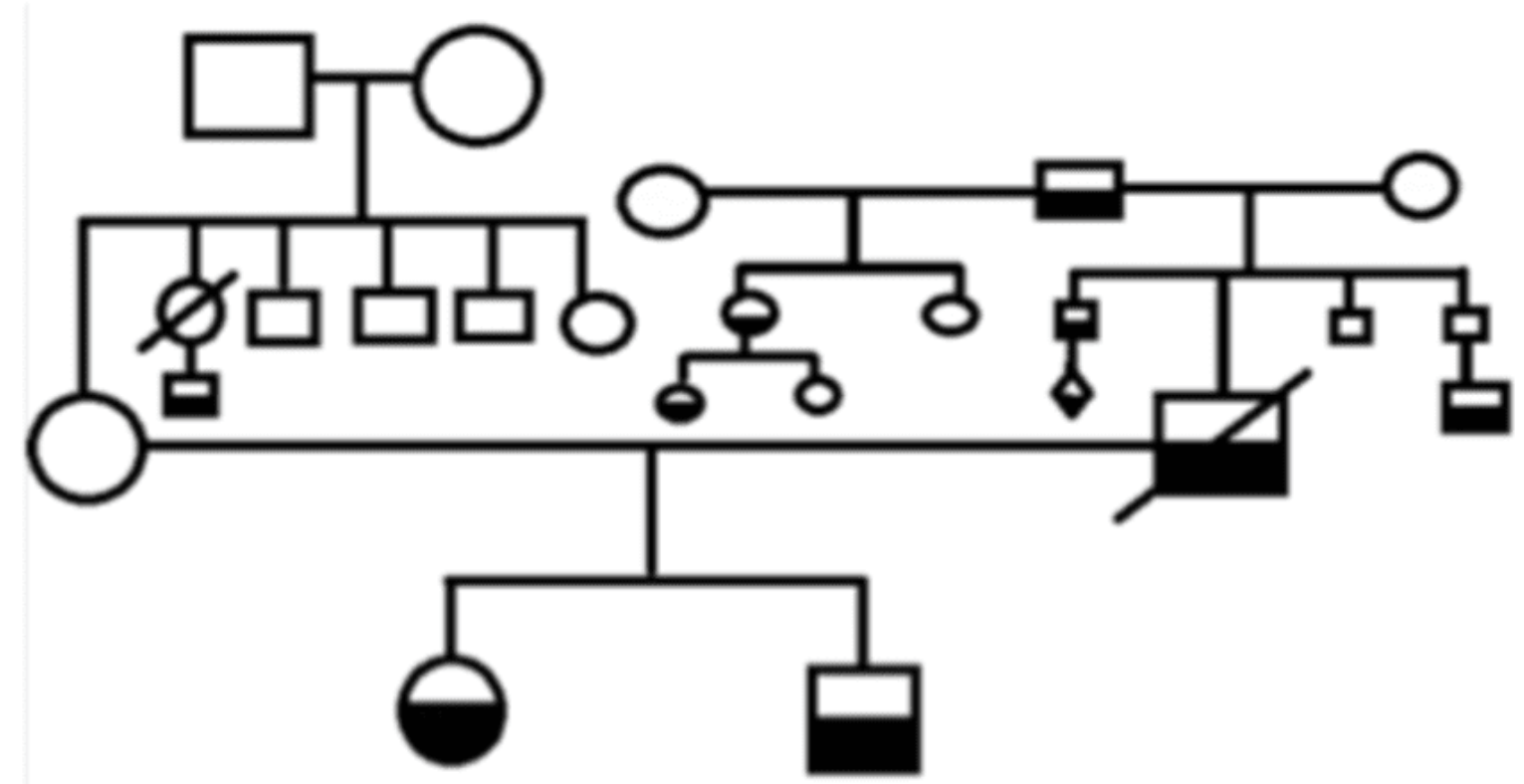

Fonte: Dados da pesquisa. 
Figura 2. (A) Deformidade óssea na região medial da coxa do indivíduo de 23 anos. (B) Deformidade óssea região anterior da coxa. (C) Deformidade óssea na região do punho do indivíduo de 11 anos (D) e (E) Deformidades ósseas nas escápulas do indivíduo de 9 anos de idade.

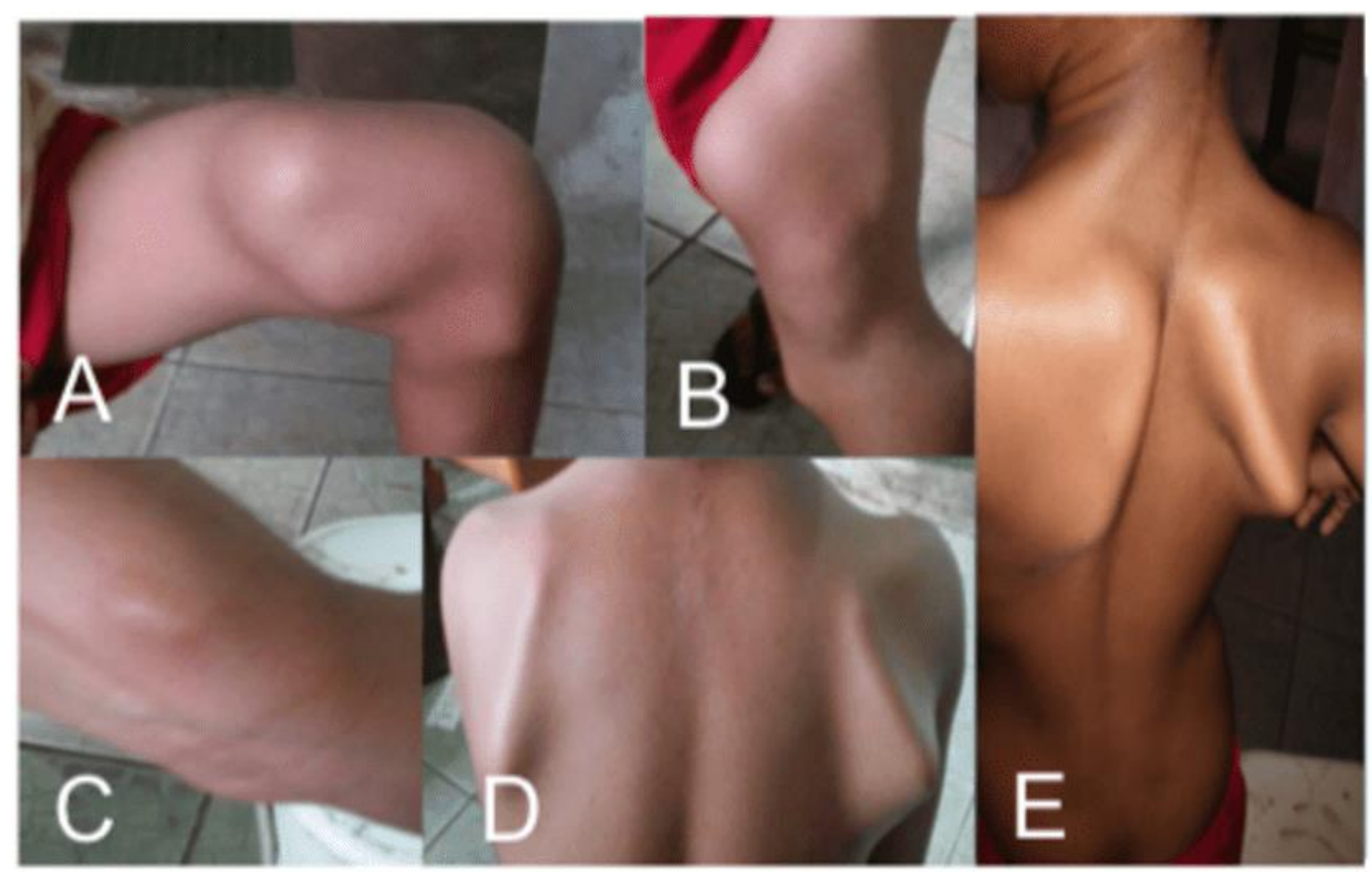

Fonte: Dados da pesquisa.

\section{CONCLUSÃO}

Embora a Osteocondromatose Hereditária seja uma doença rara, é importante que seja prontamente reconhecida, para viabilizar o adequado acompanhamento ortopédico e aconselhamento genético familiar.

Sabe-se que os osteocondromas são em sua maioria lesões benignas, e não afetam a expectativa de vida do indivíduo portador desta doença. Entretanto, o risco de malignização (paracondrossarcoma secundário) deve ser levado em consideração, principalmente nas exostoses múltiplas. 
Nos casos sintomáticos ou de localização atípica, diferentes tipos de exames radiológicos deverão sempre ser solicitadas, com o objetivo de alcançar o diagnóstico correto. Inclusive, na suspeita clínica de que possa estar ocorrendo a malignificação. Também é muito importante fazer comparações radiográficas comparando os atuais com as imagens de exames antigos. Dentre os exames radiológicos mais indicados, está a ressonância magnética, com fins de propiciar uma análise mais detalhada da grossura da capa cartilaginosa.

\section{REFERÊNCIAS}

DARILEK, S.; WICKLUND, C. NOVY, D.; SCOTT, A.; GAMBELLO, M.; JOHNSTON, D.; HECHT, J. Hereditary multiple exostosis and pain. J Pediatr Orthop. 25 (3): p. 369-76, 2005.

HARMS, S. E.; GREENWAY, G. Musculos keletal tumors. In: STARK, D. D.; BRADLEY, W. G. editors. Magnetic resonance imaging. 2nded. St Louis: Mosby Year Book, p.2132-3, 1992.

HECHT, J. T.; HOGUE, D.; STRONG, L. C.; HANSEN, M. F.; BLANTON, S. H.; WAGNER, M. Hereditary multiple exostosis and chondrosarcoma: linkage to chromosome II and loss of heterozygosity for EXT- linked markers on chromosomes II and 8. Am J Hum Genet. 56 (5): p. 1125-31, 1995.

KHURANA, J.; ABDUL- KHURANA, J. KARIM, F.; BOVÉE, J. V. M. Osteochondroma. In: Fletcher CD, UnniKK, Mertens, F, editors. Pathology and genetic sof tumours of thes of ttissues and bones. Lyon: IARC Press; p.234-7, 2002.

MURPHEY, M. D.; CHOI, J. J.; KRANSDORF, M. J.; FLEMMING, D. J.; GANNON, F. $\mathrm{H}$. Imaging of osteochondroma: variants and complications with radiologic-pathologic correlation. Radiographics. 20(5): p. 1407-34, 2000.

NICK, J. A.; LYNCH, D. A.; SCHWARZ, M. I.; HANLEY, M. E. A thoracic complication of hereditary multiple exostoses in an adult. Respir Med. 93 (3):217-9. 1999. 
SOLOMON, L. Hereditary multiple exostosis. J Bone Joint Surg.; 45B (2): 292-304, 1963.

STEINER, G. C. Benign cartilage tumors. In: TAVERAS, J. M.; FERRUCCI, J. T. editors. Radiology: diagnosis imaging intervention. Philadelphia: JB Lippincott; p.13, 1992.

WUYTS, W.; SCHMALE, G. A.; CHANSKY, H. A., et al. Hereditary Multiple Osteochondromas. 2000. Aug 3 [Update 2013 Nov 21]. In: PAGON, R. A.; ADAM, M. P.; ARDINGER, H. H. et al., editors. Gene Reviews. Seattle (WA): University of Washington, Seattle; 1993-2016.

Enviado: Dezembro, 2019.

Aprovado: Dezembro, 2019. 